\title{
Raising awareness of psychosocial factors in the occurrence of low back symptoms in developing countries
}

\author{
Baiduri Widanarko ${ }^{\mathrm{a}, \mathrm{d}, *}$, Stephen Legg $^{\mathrm{a}}$, Jason Devereux ${ }^{\mathrm{b}}$, Mark Stevenson ${ }^{\mathrm{c}}$ \\ ${ }^{a}$ Centre for Ergonomics, Occupational Safety and Health, School of Management, College of Business, Massey \\ University, Private Bag 11222, Palmerston North 4442, New Zealand \\ ${ }^{b}$ Business Psychology Unit, Department of Psychology, University College London, UK \\ ${ }^{c}$ EpiCentre, Institute of Veterinary, Animal and Biological Sciences, College of Sciences, Massey University, \\ Palmerston North, New Zealand \\ ${ }^{d}$ Department of Occupational Health and Safety, Faculty of Public Health, Universitas Indonesia, Depok 16424, \\ Indonesia
}

\begin{abstract}
Although there is strong evidence that single physical, psychosocial and organisational risk factors are each independent predictors of low back symptoms (LBS), little is known about their combination/interaction, particularly in those working in developing countries. A total of 1294 Indonesian coal mining industry workers reported information about physical, psychosocial, and organisational factors using self-reported questionnaires and were placed into one of four combination exposure groups: 1) high physical (working with bent trunk; whole body vibration exposure; lifting) and high psychosocial (high effort; low reward; work stress), 2) high physical and low psychosocial, 3) low physical and high psychosocial, and 4) low physical and low psychosocial (as the reference group). The odds of LBS in the high physical and high psychosocial group was 5.15 times $(95 \%$ confidence interval 2.69-9.86) that of the reference group. Psychosocial factors played a more important role than physical factors in increasing the likelihood of reporting LBS. Permanent and night shift workers were more likely to report LBS. These findings imply that efforts to reduce LBS in this workplace should address both psychosocial and physical factors but psychosocial factors should be the priority, with a special focus on permanent and night shift workers.
\end{abstract}

Keywords: musculoskeletal disorders; discomfort; back pain; blue-collar workers; coal mining

${ }^{*}$ Corresponding author. Email: baiduri@ui.ac.id or B.Widanarko@massey.ac.nz 


\section{Introduction}

Various physical and psychosocial risk factors are known to be predictors for low back symptoms (LBS) but there may be combinations/interactions that may influence each other $[1,2]$. To our knowledge only five studies [3-7] have investigated physical and psychosocial risk factor combinations/interactions with LBS. All of these have been conducted in developed countries and have shown that individuals exposed to both high physical and high psychosocial factors have the highest risk of LBS. They also indicated that physical factors appear to be more prominent than psychosocial factors in increasing the risk of LBS. As far as we are aware, there are no previous studies that have examined this combinations/interaction in industrially developing countries (IDCs). Thus, the objective of the present study was to examine the combination of physical and psychosocial risk factors for LBS in an IDC.

\section{Methods}

The study was conducted in a large coal mining contractor company in Indonesia. Invitations to participate were delivered in person to 2150 coal mining workers involved in light and heavy physical workloads at three sites (two located in provinces of East Borneo and one in a province in South Borneo). A self-administered questionnaire was used to obtain information on physical, psychosocial, and organisational factors, LBS, demographic characteristics (age and gender) and any accident(s) that involved the low back region. Since the original questions were in English and the study was conducted in Indonesia (n), a cross-cultural adaptation of the questionnaire was undertaken [8].

Physical exposures for their current working place were assessed by asking participants to estimate how much working time during their work activities they were involved in any of these situations: sitting position trunk bent; trunk bent and twisted; exposure to whole body vibration, and also whether their work involved lifting or carrying at least 10,6 to 15,16 to 25 , or $>25 \mathrm{~kg}$. Psychosocial exposures were assessed using the Job Content Questionnaire (JCQ) [9] and the short version of the Effort/Reward Imbalance (ERI) Questionnaire [10]. Information about job satisfaction was obtained by the Copenhagen Psychosocial Questionnaire II [11]. An additional single question on perceived work stress was also asked [12]. Organisational exposure was assessed by asking about current employment status (permanent; non-permanent) and shift work (no shift work; shift work without a night shift; shift work with a night shift). Questions about LBS were asked using the Standardised Nordic Musculoskeletal Questionnaire [13]. LBS was defined as any symptoms (such as aches, pains, discomfort, numbness or fatigue) during the last 12 month with symptoms more than 7 days and onset during the current job and also present within the last 7 days at the time of the survey.

All participants were grouped into one of four combination exposure groups: 1) high physical (working with bent trunk; whole body vibration exposure; lifting) and high psychosocial (high effort; low reward; work stress), 2) high physical and low psychosocial, 3) low physical and high psychosocial, 4) low physical and low psychosocial group (the reference group). Workers that did not fulfil the criteria for classification into the high or low exposure group were classified into an unclassified group and excluded from the analysis. Logistic regression was used to obtain the final model for combination of the risk factors. Organisational factors, age, and gender were included in the final model. All statistical analyses were conducted using Predictive Analytics Software version 18.0 [14].

\section{Results}

Of the 1294 valid questionnaires, 96\% were male $(n=1252)$. The median age was 26 with interquartile range 23-33 years. Fifty-eight percent of the sample had worked for $<3$ years, $18 \%$ for $3-5$ years, and $24 \%$ for $>5$ years.

A total of 1070 participants were classified into one of the four combination exposure groups. Those in the high physical and high psychosocial group $(n=47)$ had the highest odds ratio for LBS (OR 5.15 $95 \%$ CI 2.69-9.86). The group with high physical and low psychosocial exposure $(n=61)$ (OR 2.75 95\% CI 1.43-5.27) was less likely to report LBS than groups with low physical and high psychosocial exposure $(n=303)$ (2.89 95\% CI 2.02-4.14). Non-permanent employees were less likely to report LBS (0.66 95\% $0.46-0.95$ ). Night shift workers (OR 1.77 95\% CI 1.07-2.93) were more likely to report LBS. 


\section{Discussion}

Combined exposure to physical and psychosocial work risk factors increased the risk of LBS in the present study. The nature of combined exposure allowed us to characterise the interactions among exposures, but this is beyond of the scope of this paper. Individuals with both high physical and high psychosocial exposures were most likely to report LBS. Although it is difficult to compare this finding with other studies due to differences in risk factor criteria and the natures of the populations studied, it is in agreement with cross-sectional studies among working populations in Sweden [7] and the UK [3, 4] and US Marines [5]. However, the present study also found that a high psychosocial exposure was necessary to increase the likelihood of reporting LBS. This finding differs from previous studies which have almost exclusively been conducted in developed countries and which have found that physical factors play a more important role in increasing the possibility of reporting LBS [3-7]. This may be due to globalisation which has impacted developing countries in many sectors, particularly including the socio-economic sector. To be able to compete globally, IDCs may have to face the challenge of managing the changing nature of work, such as the demands of flexible contracts, increased job insecurity, a high work pace, long and irregular working hours, low income, etc. [15]. This, in turn, may increase psychosocial problems and stress at work for workers in IDCs. Additionally, employers in IDCs may lack awareness of psychosocial factors and stress at work [16]. They may thus be unaware of the importance of managing these and may not have put in place any prevention strategies.

In conclusion, the present study has shown that Indonesian coal mining workers with both high physical and high psychosocial exposures were most likely to report LBS. It also showed that a high psychosocial exposure increased the likelihood of reporting LBS and that permanent employees and night shift workers were more likely to report LBS. The findings imply that efforts to reduce LBS in this workplace should address both physical factors (i.e. reducing working with a bent trunk posture, working on an unstable surface, and lifting) and psychosocial factors (i.e. reducing the worker's effort, increasing reward and managing work stress) with a focus on permanent employees and night shift workers. It is logical to suppose that similar conclusions might apply for other industries in other IDCs.

\section{References}

[1] K.G. Davis, C.A. Heaney, The relationship between psychosocial work characteristics and low back pain: underlying methodological issues, Clinical Biomechanics, 15 (2000) 389-406.

[2] B.-T. Karsh, Theories of work-related musculoskeletal disorders: Implications for ergonomic interventions, Theoretical Issues in Ergonomics Science, 7 (2006) 71-88.

[3] J.J Devereux, P.W Buckle, I.G. Vlachonikolis, Interactions between physical and psychosocial work risk factors increase the risk of back disorders: an epidemiological approach Occupational and Environmental Medicine, 56 (1999) 343353.

[4] J. Devereux, L. Rydstedt, V. Kelly, P. Weston, P. Buckle, The role of work stress and psychological factors in the development of musculoskeletal disorders: The stress and MSD study (RR 273), in, Health and Safety Executive. http://www.hse.gov.uk/research/rrhtm/rr273.htm, 2004.

[5] G.D. Huang, M. Feuerstein, W.J. Kop, K. Schor, F. Arroyo, Individual and combined impacts of biomechanical and work organization factors in work-related musculoskeletal symptoms, American Journal of Industrial Medicine, 43 (2003) 495-506.

[6] J. Lapointe, C.E. Dionne, C. Brisson, S. Montreuil, Interaction between postural risk factors and job strain on self-reported musculoskeletal symptoms among users of video display units: a three-year prospective study, Scan J Work Environ Health, 35 (2009) 134-144.

[7] S.J. Linton, Risk-factors for neck and back pain in a working population in Sweden, Work and Stress, 4 (1990) 41-49.

[8] D.E. Beaton, C. Bombardier, F. Guillemin, M.B. Ferraz, Guidelines for the process of cross-cultural adaptation of selfreport measures, Spine, 25 (2000) 3186-3191.

[9] R. Karasek, C. Brisson, N. Kawakami, I. Houtman, P. Bongers, B. Amick, The Job Content Questionnaire (JCQ): An Instrument for Internationally Comparative Assessments of Psychosocial Job Characteristics, Journal of Occupational Health Psychology, 3 (1998) 322-355.

[10] J. Siegrist, N. Wege, F. Pühlhofer, M. Wahrendorf, A short generic measure of work stress in the era globalization: efforreward imbalance, Int Arch Occup Environ Health, 82 (2008) 1005-1013.

[11] J.H. Pejtersen, T.S. Kristensen, V. Borg, J.B. Bjorner, The second version of the Copenhagen Psychosocial Questionnaire, Scandinavian Journal of Public Health, 38 (2010) 8-24.

[12] A. Smith, S. Johal, E. Wadsworth, G. Davey Smith, I. Harvey, T. Peters, The scale of occupational stress, Occup Health Review, 73 (1998) 19-22.

[13] I. Kuorinka, B. Jonsson, A. Kilbom, H. Vinterberg, F. Biering-Sørensen, G. Andersson, K. Jørgensen, Standardised Nordic questionnaires for the analysis of musculoskeletal symptoms, Applied Ergonomics, 18 (1987) 233-237.

[14] Predictive Analytics Software (PASW) Statistics 18, Release 18.0.0, in, SPSS Inc., an IBM Company, Chicago, 2009.

[15] I.L. Houtman, K. Jettinghoff, L. Cedillo, Raising awareness of stress at work in developing countries - a modern hazard in a traditional working environment (Protecting Workers' Health Series No 6), World Health Organization, Geneva, 2008 .

[16] E. Kortum, S. Leka, T. Cox, Perceptions of psyhcosocial hazards, work-related stress and workplace priority risks in developing counties, Journal of Occupational Health, 53 (2011)144-155. 